\title{
PD-L1 expression in renal cell carcinoma clear cell type is related to unfavorable prognosis
}

\author{
Katia R M Leite ${ }^{1,2^{*}}$, Sabrina T. Reis ${ }^{1}$, José Pontes Junior ${ }^{1}$, Marcelo Zerati ${ }^{1}$, Daniel de Oliveira Gomes ${ }^{1}$, \\ Luiz H. Camara-Lopes ${ }^{2}$ and Miguel Srougi ${ }^{1}$
}

\begin{abstract}
Background: PD-L1 is a glycoprotein from the family of T-cell co-stimulatory molecules that are constitutively expressed by macrophages. Aberrant expression of PD-L1 is observed in human cancers associated with inhibition of the tumor-directed T-cell immune response. There are few reports in the literature evaluating PD-L1 expression in association to prognosis specifically in renal cell cancer clear cell type (RCC-CC).

Methods: Immunohistochemistry using a PD-L1 polyclonal antibody was performed on a tissue microarray (TMA) that contained 115 surgical specimens of RCC-CC. Cases were classified based on the absence or presence of staining intensity in the cytoplasm and membranes of the tumor cells. Statistical analysis was used to determine the association of PD-L1 expression with classic prognostic factors and tumor recurrence.
\end{abstract}

Results: PD-L1 expression was positive in $56.5 \%$ of tumors. The univariate analysis showed a correlation between PD-L1 expression and nuclear Fuhrman grade $(p=0.021)$ and microvascular tumor embolization $(p=0.039)$. One hundred and four patients were monitored for a mean time of 115.7 months. Seventeen patients (16.3\%) suffered tumor recurrence. Negative outcomes were associated with higher nuclear grade tumors, PD-L1 expression, and the presence of microvascular invasion.

Conclusion: Our findings confirm that PD-L1 expression is an important prognostic factor in RCC-CC.

Keywords: Renal cell cancer, PD-L1, Prognosis, Immunotherapy, Immunohistochemistry

\section{Background}

Recently, the capacity of neoplastic cells to evade immunological destruction became an additional checkpoint in assessing the hallmarks of cancer [1]. T cells play the most important role in this context; the recognition of tumorassociated antigens by healthy $\mathrm{T}$ cells allows the activation of a specific anti-tumor immune reaction. CD8+ effector $\mathrm{T}$ cells, known as cytotoxic $\mathrm{T}$ lymphocytes (CTLs), are the main players in this process. Two receptors, cytotoxic T-lymphocyte-associated antigen 4 (CTLA4) and programmed cell death protein 1 (PD-1), have been actively studied in cancer for their potential roles as inhibitory receptors. Blockage of these receptors by antibodies has been studied in numerous clinical trials with promising results $[2,3]$.

\footnotetext{
*Correspondence: katiaramos@uol.com.br

'Department of Urology, Laboratory of Medical Research, University of São Paulo Medical School, Sao Paulo, Brazil

${ }^{2}$ Department of Molecular Biology, Genoa Biotecnologia SA, Av Dr. Arnaldo \#455, room 2145, 01246-903 Sao Paulo, Brazil
}

PD-1 is a 288-amino acid cell-surface protein. PD-1 binds two ligands, PD-L1 and PD-L2, which negatively regulate the immune response. The expression of PD-L1 (also known as B7-H1) on tumor cells leads to the inhibition of the $\mathrm{T}$ cell-mediated immune response against cancer, thereby enabling tumor progression and metastasis $[4,5]$.

Expression of PD-L1 has been correlated with poor clinical outcomes in a number of human cancers [6], including renal cell cancer (RCC) [7]. As a result, it has been considered a potential predictive biomarker and has inspired new drug development designed to block PD-1.

Immunotherapy was the leading strategy for treating RCC until recently, when targeted inhibitors of the VEGF (Vascular endothelial growth factor) and mTOR pathway began to show promising results. These therapeutic inhibitors increased progression-free and overall survival rates, but failed to show a durable response. Blocking the PD-1-PD-L1 interaction with monoclonal antibodies, however, restores the activity of $\mathrm{T}$ cells within 
the tumor microenvironment and has been shown to result in a significant and sustained antitumor response in clinical trials [8].

Our aim is to study the PD-L1 expression in RCC clear cell type (RCC-CC) and how that expression correlates with prognostic factors and tumor recurrence.

\section{Methods}

The Institutional Internal Review Board approved this study (process number 1,034,579). We retrospectively analyzed surgical specimens from 148 patients diagnosed with localized (NX-0 M0) RCC-CC who underwent radical or conservative renal surgery (partial nephrectomy or tumor enucleation) between 1988 and 2006 at our institution. Data and adequate material for examination were available for 115 patients, and the clinical and pathological characteristics are shown in Table 1. For staging purposes, lymph node dissection was limited to the hilar region in those who underwent radical nephrectomy. The same surgeon (MS) operated on all patients and all pathological analyses were performed by the same uropathologist (KRML). Patients with systemic metastatic disease at the time of surgery were excluded from the study. For each patient, the analyzed clinical and pathological characteristics included age, gender, symptoms at initial presentation, tumor size, pT stage (2010 TNM classification), Fuhrman nuclear grade, nucleolar grade as recently recommended by International Society of Urological Pathology (ISUP) [9], coagulative tumor necrosis, and microvascular invasion. Following surgery, all patients appeared for regular follow-up visits based on their staging. Low-risk patients returned for semi-annual physical examinations and routine blood tests in addition to annual chest radiography and abdominal computed tomography. Chest tomography, bone scintigraphy, and brain imaging were conducted in clinically applicable cases.

The tissue microarray (TMA) was constructed as previously described [10]. Using a precision mechanical system (Beecher Instruments, Sun Prairie, WI), tissue cylinders with a diameter of $0.6 \mathrm{~mm}$ were removed from each patient's paraffin block containing the RCC-CC from specific areas, corresponding to the previously demarcated, most representative areas from respective hematoxylin-eosin-stained slides. These cylinders were transferred with 3-mm intervals to a recipient paraffin block. Next, the tissue microarray recipient block was cut into 3- $\mu \mathrm{m}$ histologic section, and this slide was used for immunohistochemistry. Two tumor samples were collected per patient, because it has been demonstrated that analysis of 2 disks is comparable to the analysis of a whole tissue section in more than $95 \%$ of cases [11].

Immunohistochemical analysis was performed using BOND III Leica equipment (Leica Biosystems) using
Table 1 Clinical and pathological characteristics of 115 patients with renal cell cancer, clear cell type studied for the presence of PD-L1 immune-expression

\begin{tabular}{|c|c|}
\hline & $N(\%)$ \\
\hline \multicolumn{2}{|l|}{ Age (years old) } \\
\hline Mean (SD) & $57.7(11.5)$ \\
\hline \multicolumn{2}{|l|}{ Gender } \\
\hline Male & $91(79.1)$ \\
\hline Female & 24(20.9) \\
\hline \multicolumn{2}{|l|}{ Tumor size $(\mathrm{cm})$} \\
\hline Mean (SD) & $4.8(2.9)$ \\
\hline \multicolumn{2}{|l|}{ Tumor stage } \\
\hline pT1 & $80(69.6)$ \\
\hline pT2 & $8(7.0)$ \\
\hline pT3 & $27(23.4)$ \\
\hline Metastasis to lymph nodes & $6(5.2)$ \\
\hline \multicolumn{2}{|l|}{ Fuhrman nuclear grade } \\
\hline 1 & $25(21.7)$ \\
\hline 2 & 44(38.3) \\
\hline 3 & $41(35.7)$ \\
\hline 4 & $5(4.3)$ \\
\hline \multicolumn{2}{|l|}{ Nucleolar grade } \\
\hline 1 & $22(19.1)$ \\
\hline 2 & $47(40.9)$ \\
\hline 3 & $46(40.0)$ \\
\hline \multicolumn{2}{|l|}{ Microvascular invasion } \\
\hline Absent & $83(72.2)$ \\
\hline Present & $32(27.8)$ \\
\hline \multicolumn{2}{|l|}{ Tumor necrosis } \\
\hline Absent & $91(79.1)$ \\
\hline Present & 24(20.9) \\
\hline \multicolumn{2}{|l|}{ Presentation } \\
\hline Incidental & $76(66.1)$ \\
\hline Symptoms & 39(33.9) \\
\hline
\end{tabular}

the polyclonal antibody anti-PD-L1 (ABCAM) in a 1:25 dilution.

Statistical analysis was performed using SPSS version 19.0 software. Differences between groups were evaluated using a $X^{2}$ test. Time to recurrence was calculated using the Kaplan-Meier method. The differences between the curves were measured using a log-rank test. Two-tailed tests were used and a p-value $<0.05$ was considered to be significant.

\section{Results}

PD-L1 was diffusely expressed in the cytoplasm and membrane of tumor cells in $65(56.5 \%)$ of assessed cases. The staining was weak in 29 (44.6\%), moderate in 
15 (23.1 \%) and strong in 21 (32.3\%) of the cases (Fig. 1). For statistical analysis, we considered any intensity of staining as positive and compared these results with cases that were completely negative for staining. The univariate analysis showed correlation between PD-L1 expression and higher nuclear Fuhrman grade $(p=0.021)$ and microvascular tumor embolization $(p=0.039)$. The results are expressed in Table 2. Although there was no correlation between PD-L1 expression and any other of the tested negative prognostic factors, in the few cases in which lymph node metastasis was present, PD-L1 was expressed in $67 \%$ of the cases. PD-L1 was also expressed in $83 \%$ of cases that developed distant metastasis and in $65 \%$ of cases that showed tumor recurrence.

One hundred and four patients were followed for a mean time of 115.7 months. Seventeen (16.3\%) of the followed cases suffered tumor recurrence. Tumor size $(8.6 \mathrm{~cm}$ vs $4.1 \mathrm{~cm} ; p<0.001)$, symptomatic presentation $(p<0.001)$, microvascular invasion $(p<0.001)$, tumor necrosis $(p=0.007)$, tumor stage $(\mathrm{pT} 2 / \mathrm{pT} 3$ vs pT1, $p<0.001)$ and the presence of lymph node metastasis $(p<0.001)$ were all factors that were related to tumor recurrence (Table 3).
We have previously described that the Fuhrman nuclear grade and microvascular tumor invasion are powerful predictors of outcome in RCC [12]. Considering these two important prognostic factors for localized RCC, we built a Kaplan-Meier curve using these parameters with the addition of PD-L1 expression. Cases were grouped as follows: 1. PD-L1 negative, no microvascular tumor invasion and low Fuhrman nuclear grade; 2. Presence of one of any of these variables; 3 . Presence of two of any of these variables; and 4. Presence of all three variables: PD-L1 expression, microvascular tumor invasion and high Fuhrman nuclear grade. The curves are shown in Fig. 2. There is clearly a higher rate of tumor recurrence in patients who were positive for these three poor prognostic factors $(p=0.007)$.

Fourteen (12.2 \%) patients died, 13 (92.9\%) of whom died as a result of RCC progression. PD-L1 was positive in 8 from these $13(61.5 \%)$ cases $(p=0.104)$. Although the relationship is not statistically significant, the small number of tumor-related deaths may have influenced the negative result.

In conclusion, PD-L1 was diffusely expressed by $56.5 \%$ of the cases related to higher nuclear Fuhrman

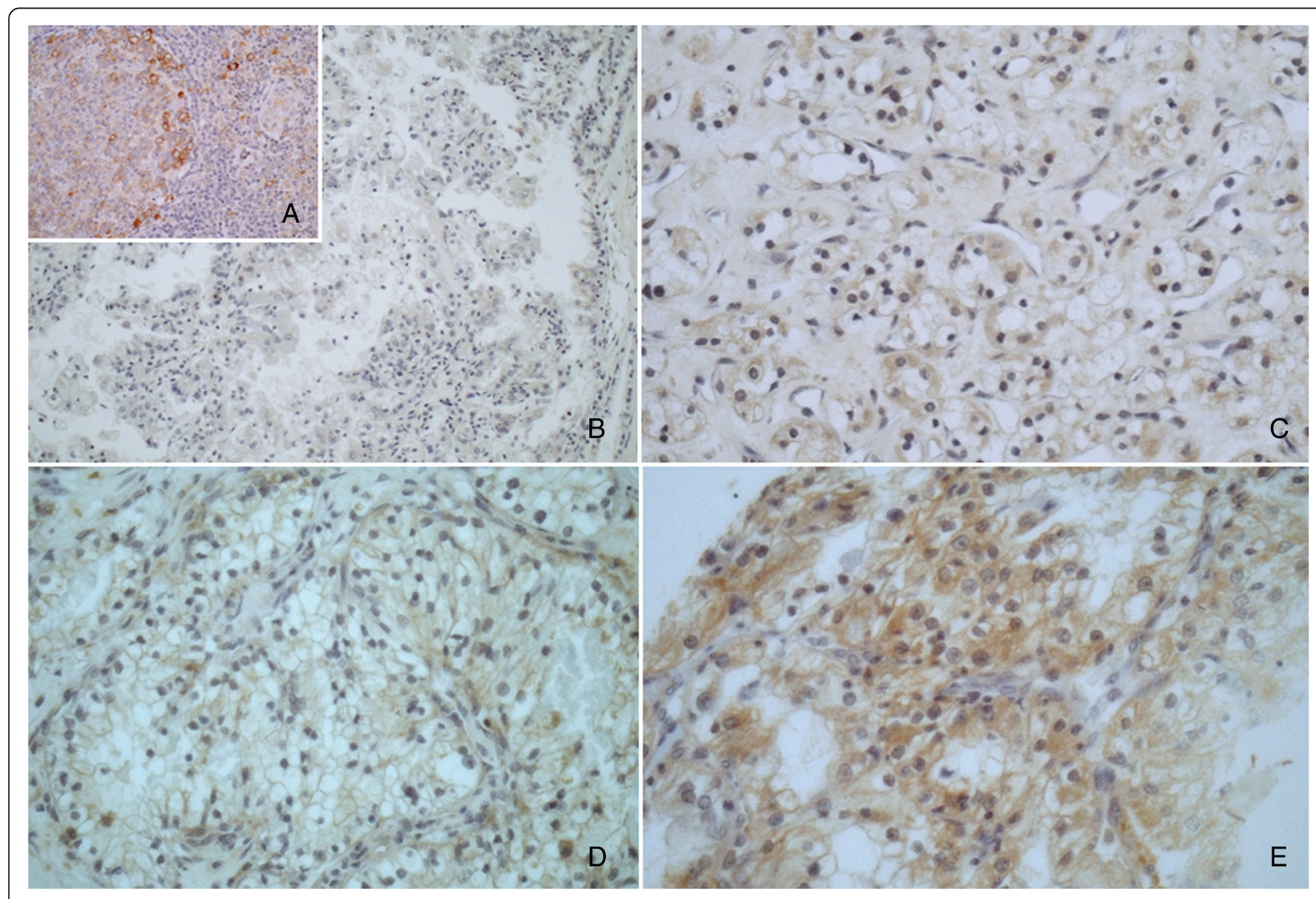

Fig. 1 Photomicrography showing PD-L1 immune-expression in RCC-CC. a Positive control, b negative control, c Positive - score 1, d Positive - score 2, e Positive - score 3 
Table 2 Correlation between PD-L1 expression and prognostic factors

\begin{tabular}{|c|c|c|c|}
\hline & PD-L1 neg & PD-L1 pos & $p$ \\
\hline \multicolumn{4}{|c|}{ Characteristics $(N=115)$} \\
\hline Age & 58.2 & 57.4 & 0.737 \\
\hline \multicolumn{4}{|l|}{ Gender } \\
\hline Female & $9(37.5)$ & $15(62.5)$ & 0.507 \\
\hline Male & $41(45.1)$ & $50(54.9)$ & \\
\hline Tumor size (cm) & 4.5 & 5.1 & 0.246 \\
\hline \multicolumn{4}{|l|}{ Presentation } \\
\hline Incidental & $34(44.7)$ & $42(55.3)$ & 0.704 \\
\hline Symptomatic & 16(41.0) & 23(59.0) & \\
\hline \multicolumn{4}{|c|}{ Fuhrman nuclear grade } \\
\hline 1,2 & $36(52.2)$ & $33(47.8)$ & 0.021 \\
\hline 3,4 & 14(30.4) & 32(69.6) & \\
\hline \multicolumn{4}{|l|}{ Nucleolar grade } \\
\hline 1 & $12(54.5)$ & $10(45.5)$ & 0.207 \\
\hline 2 & $16(34.0)$ & $31(66.0)$ & \\
\hline 3 & $22(47.8)$ & $24(52.2)$ & \\
\hline \multicolumn{4}{|c|}{ Microvascular invasion } \\
\hline Absent & $41(49.4)$ & $42(50.6)$ & 0.039 \\
\hline Present & $9(28.1)$ & 23(71.9) & \\
\hline \multicolumn{4}{|l|}{ Tumor necrosis } \\
\hline Absent & $41(45.1)$ & $50(54.9)$ & 0.507 \\
\hline Present & $9(37.5)$ & $15(62.5)$ & \\
\hline \multicolumn{4}{|l|}{ Tumor stage } \\
\hline pT1 & $38(47.5)$ & $42(52.5)$ & 0.188 \\
\hline pT2,3 & $12(34.3)$ & 23(65.7) & \\
\hline \multicolumn{4}{|c|}{ Metastasis to lymph nodes } \\
\hline Absent & $48(44.0)$ & $61(56.0)$ & 0.607 \\
\hline Present & $2(33.3)$ & $4(66.7)$ & \\
\hline \multicolumn{4}{|c|}{ Development of distant metastasis } \\
\hline Absent & $49(45.0)$ & $60(55.0)$ & 0.174 \\
\hline Present & $1(16.7)$ & $5(83.3)$ & \\
\hline \multicolumn{4}{|c|}{ Tumor recurrence $(N=104)$} \\
\hline Absent & $39(44.8)$ & $48(55.2)$ & 0.468 \\
\hline Present & $6(35.3)$ & $11(64.7)$ & \\
\hline
\end{tabular}

grade $(p=0.021)$ and microvascular tumor embolization $(p=0.039)$ in univariate analysis.

\section{Discussion}

PD-L1 expression has been studied as a biomarker of response to the new PD-1/PD-L1 inhibitors in different tumors, but its prognostic value is not yet well established.

Our study showed that PD-L1 was expressed in $56.5 \%$ of RCC-CC cases and positive expression was correlated with a higher Fuhrman nuclear grade and microvascular
Table 3 Clinical and pathological characteristics of patients considering tumor recurrence

\begin{tabular}{|c|c|c|c|}
\hline Tumor recurrence $(N=104)$ & $\mathrm{No}(87)$ & Yes(17) & $p$ \\
\hline \multicolumn{4}{|l|}{ Characteristics } \\
\hline Age (mean-yo) & 57.7 & 60.1 & 0.436 \\
\hline \multicolumn{4}{|l|}{ Gender } \\
\hline Female & $21(24.1)$ & $3(17.6)$ & \multirow[t]{2}{*}{0.561} \\
\hline Male & $66(75.9)$ & $14(82.4)$ & \\
\hline Tumor size (mean-cm) & 4.1 & 8.6 & $<0.001$ \\
\hline \multicolumn{4}{|l|}{ Presentation } \\
\hline Incidental & $64(73.6)$ & $4(23.5)$ & \multirow[t]{2}{*}{$<0.001$} \\
\hline Symptomatic & $23(26.4)$ & 13(76.5) & \\
\hline \multicolumn{4}{|l|}{ Fuhrman nuclear grade } \\
\hline 1,2 & $57(65.5)$ & $8(47.1)$ & \multirow[t]{2}{*}{0.150} \\
\hline 3,4 & $30(34.5)$ & $9(52.9)$ & \\
\hline \multicolumn{4}{|l|}{ Nucleolar grade } \\
\hline 1 & 17(19.5) & $2(11.8)$ & \multirow[t]{3}{*}{0.743} \\
\hline 2 & $36(41.4)$ & $8(47.1)$ & \\
\hline 3 & 24(39.1) & $7(41.2)$ & \\
\hline \multicolumn{4}{|l|}{ Microvascular invasion } \\
\hline Absent & $70(80.5)$ & $5(29.4)$ & \multirow[t]{2}{*}{$<0.001$} \\
\hline Present & $17(19.5)$ & $12(70.6)$ & \\
\hline \multicolumn{4}{|l|}{ Tumor necrosis } \\
\hline Absent & $72(82.8)$ & $9(52.9)$ & \multirow[t]{2}{*}{0.007} \\
\hline Present & $15(17.2)$ & $8(47.1)$ & \\
\hline \multicolumn{4}{|l|}{ Tumor stage } \\
\hline pT1 & $70(80.5)$ & $5(29.4)$ & \multirow[t]{2}{*}{$<0.001$} \\
\hline $\mathrm{pT} 2,3$ & $17(19.5)$ & 12(70.6) & \\
\hline \multicolumn{4}{|l|}{ Metastasis to lymph nodes } \\
\hline Absent & $86(98.9)$ & 13(76.5) & \multirow[t]{2}{*}{$<0.001$} \\
\hline Present & $1(1.1)$ & $4(23.5)$ & \\
\hline \multicolumn{4}{|l|}{ PDL1 } \\
\hline Negative & $39(44.8)$ & $6(35.3)$ & \multirow[t]{2}{*}{0.468} \\
\hline Positive & $48(55.2)$ & $11(64.7)$ & \\
\hline
\end{tabular}

tumor embolization. In addition, PD-L1 analysis provided information about the relationship between tumor outcome and higher rates of tumor recurrence when associated with these two other tested prognostic factors.

In 1999, Dong et al. described PD-L1 as a cell-surface glycoprotein within the B7 family of T-cell co-stimulatory molecules that is constitutively expressed by macrophagelineage cells [13]. Since then, studies have shown aberrant expression of PD-L1 in various human cancers, including breast, ovarian, lung, and colon cancer, in addition to lymphoma and melanoma [14]. Tumor cells that express PD-L1 have been shown to inhibit tumor-specific T-cellmediated immunity by inducing $\mathrm{T}$-cell apoptosis, impairing 


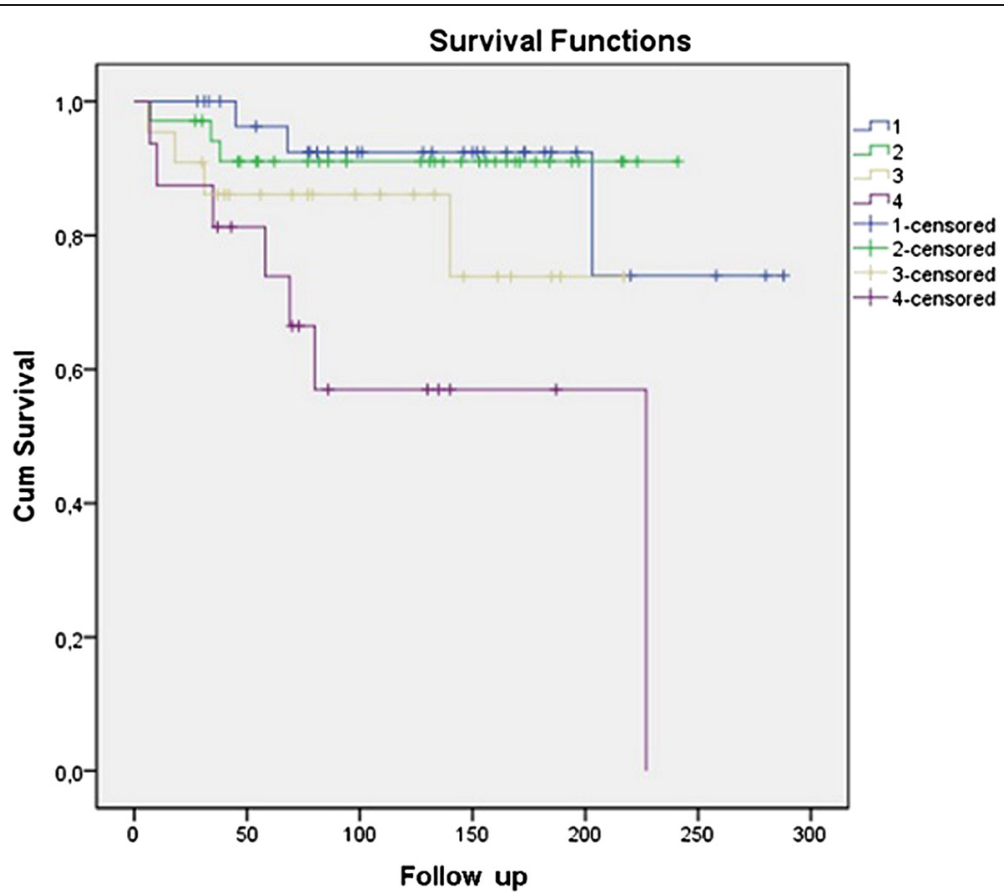

Fig. 2 Kaplan-Meier curve of tumor recurrence. The blue line represents tumors negative for PD-L1 with no microvascular tumor invasion and low nuclear grade. The green line represents tumors with one of the following: PD-L1 expression, microvascular tumor invasion, or high nuclear grade. The yellow line represents tumors with two of these variables, and the purple line represents tumors with all three unfavorable prognostic factors $(p=0.007)$

cytokine production, and diminishing the cytotoxicity of activated T cells [15].

There are few reports in the literature evaluating the relationship between PD-L1 expression and clinical prognosis in $\mathrm{RCC}$, and the majority of existing reports relates expression with other known poor prognosis factors and negative outcome.

Thompson et al. were the first to study PD-L1 expression by immunohistochemistry in RCC, finding $24 \%$ of staining associated with adverse pathologic features, including higher tumor stage, greater tumor size, a Fuhrman nuclear grade of 3 or 4, and tumor necrosis [16]. In addition, by evaluating the expression levels of PD-L1 in tumor cells alone, in lymphocytes alone, or in tumor and/or lymphocytes combined, researchers have shown an association between PD-L1 positivity with aggressive tumor behavior and increased risk of death from RCC [17].

Choueiri et al. showed that PD-L1 expression is related to shorter survival times in patients with metastatic RCC who were receiving VEGF-targeted agents, therefore arguing that PD-L1 expression should be considered in the design of future clinical trials [18].

Interestingly a study published by Jilaveanu et al. [19] compared PD-L1 in 34 cases of primary and metastatic RCC showing no correlation between paired specimens.
They advocate that the result of primary tumor regarding PD-L1 expression is not appropriate to predict response to the new PD-L1 inhibitors.

In non-clear cell RCC patients with PD-L1 tumor expression is associated with higher tumor stage and grade and worse clinical outcomes [20].

In breast cancer, PD-L1 was upregulated in $20 \%$ of cases and was related to poor-prognostic features such as tumor size, high grade, estrogen and progesterone negativity, Her2/Neu positivity and higher rates of cell proliferation, although upregulation of PD-L1 was not associated with survival of patients in this study [21].

In gastric cancer, PD-L1 was positively expressed in $50 \%$ of cases associated with higher $\mathrm{T}$ stage, lymphnode metastasis and overall survival [22].

A meta-analysis study of non-small cell lung cancer indicated that PD-L1 expression is associated with tumor differentiation and lower overall patient survival [23].

The fact that we used a TMA to indicate PD-L1 expression should be a point of criticism; however, in studies of other tumor markers, the representation of two cores has been shown to generally be similar to a whole tissue fragment, with the advantage of standardization in the immunohistochemistry reaction [11]. The small number of cases, particularly the small number of cancer deaths, may reflect some percentage of error in TMA- 
based PD-L1 analysis, which may explain the absence of a positive result regarding PD-L1 expression and tumor prognosis in this statistical analysis.

\section{Conclusion}

In conclusion, this report confirms, using immunohistochemistry, that PD-L1 expression represents a new marker of prognosis in RCC-CC.

\section{Abbreviation}

RCC-CC: Renal cell cancer clear cell type; CTL: Cytotoxic T lymphocytes; CTLA4: C ytotoxic T-lymphocyte-associated antigen 4; PD-1: Programmed cell death protein 1; PD-L1: Programmed cell death protein ligand 1; VEGF: Vascular endothelial growth factor; mTOR: Mammalian target of rapamycin; TMA: Tissue microarray.

\section{Competing interests}

The authors declare that they have no competing interests.

\section{Authors' contributions}

KRML: Study design, slides interpretation and draft of the manuscript. STR: Statistical analysis. JPJR: Preparation of the TMA and patients follow up. MZ: Preparation of the TMA and patients follow up. DOG: Preparation of the TMA and patients follow up. LHCL: Slides interpretation and study supervision. MS: Surgical treatment and follow up of the patients. Study supervision. All authors read and approved the final manuscript.

Received: 6 July 2015 Accepted: 1 October 2015

Published online: 15 October 2015

\section{References}

1. Hanahan D, Weinberg RA. Hallmarks of cancer: The next generation. Cell. 2011;144:646-74

2. Topalian SL, Hodi FS, Brahmer JR, et al. Safety, activity, and immune correlates of anti-pd-1 antibody in cancer. N Engl J Med. 2012;366:2443-54.

3. Brahmer JR, Tykodi SS, Chow LQ, Hwu WJ, Topalian SL, Hwu P, et al. Safety and activity of anti-pd-11 antibody in patients with advanced cancer. N Engl J Med. 2012;366:2455-65.

4. Drake CG, Jaffee E, Pardoll DM. Mechanisms of immune evasion by tumors. Adv Immunol. 2006;90:51-81.

5. Pardoll DM. The blockade of immune checkpoints in cancer immunotherapy. Nat Rev Cancer. 2012;12:252-64.

6. Zou W, Chen L. Inhibitory b7-family molecules in the tumour microenvironment. Nat Rev Immunol. 2008;8:467-77.

7. Thompson RH, Dong H, Lohse CM, Leibovich BC, Blute ML, Cheville JC, et al. $\mathrm{Pd}-1$ is expressed by tumor-infiltrating immune cells and is associated with poor outcome for patients with renal cell carcinoma. Clin Cancer Res. 2007;13:1757-61.

8. Gunturi A, McDermott DF. Potential of new therapies like anti-pd1 in kidney cancer. Curr Treat Options in Oncol. 2014;15:137-46.

9. Delahunt B, Cheville JC, Martignoni G, Humphrey PA, Magi-Galluzzi C, McKenney J, et al. Members of the ISUP Renal Tumor Panel. The International Society of Urological Pathology (ISUP) grading system for renal cell carcinoma and other prognostic parameters. Am J Surg Pathol. 2013;37:1490-504.

10. Moch H, Schraml P, Bubendorf L, Mirlacher M, Kononen J, Gasser T, et al. High-throughput tissue microarray analysis to evaluate genes uncovered by CDNA microarray screening in renal cell carcinoma. Am J Pathol. 1999;154:981-6.

11. Camp RL, Charette LA, Rimm DL. Validation of tissue microarray technology in breast carcinoma. Lab Invest. 2000;80:1943-9.

12. Dall'Oglio MF, Ribeiro-Filho LA, Antunes AA, Crippa A, Nesrallah L, Gonçalves $P D$, et al. Microvascular tumor invasion, tumor size and fuhrman grade: a pathological triad for prognostic evaluation of renal cell carcinoma. J Urol. 2007;178:425-8. discussion 428 .

13. Dong H, Zhu G, Tamada K, Chen L. B7-h1, a third member of the b7 family, co-stimulates t-cell proliferation and interleukin-10 secretion. Nat Med. 1999;5:1365-9.
14. Dong H, Strome SE, Salomao DR, Tamura H, Hirano F, Flies DB, et al. Tumorassociated B7-H1 promotes T-cell apoptosis: a potential mechanism of immune evasion. Nat Med. 2002;8:793-800.

15. Iwai Y, Ishida M, Tanaka Y, Okazaki T, Honjo T, Minato N. Involvement of pd-11 on tumor cells in the escape from host immune system and tumor immunotherapy by pd-11 blockade. Proc Natl Acad Sci U S A. 2002;99:12293-7.

16. Thompson RH, Kuntz SM, Leibovich BC, Dong H, Lohse CM, Webster WS, et al. Tumor B7-H1 is associated with poor prognosis in renal cell carcinoma patients with long-term follow-up. Cancer Res. 2006;66:3381-5.

17. Thompson RH, Gillett MD, Cheville JC, Lohse CM, Dong H, Webster WS, et al, et al. Costimulatory B7-H1 in renal cell carcinoma patients: Indicator of tumor aggressiveness and potential therapeutic target. Proc Natl Acad Sci U S A. 2004:101:17174-9.

18. Choueiri TK, Figueroa DJ, Fay AP, Signoretti S, Liu Y, Gagnon R, et al. Correlation of PD-L1 tumor expression and treatment outcomes in patients with renal cell carcinoma receiving sunitinib or pazopanib: results from COMPARZ, a randomized controlled trial. Clin Can Res. 2015;21:1071-7.

19. Jilaveanu LB, Shuch B, Zito CR, Parisi F, Barr M, Kluger Y, et al. PD-L1 Expression in Clear Cell Renal Cell Carcinoma: An Analysis of Nephrectomy and Sites of Metastases. J Cancer. 2014;5:166-72.

20. Choueiri TK, Fay AP, Gray KP, Callea M, Ho TH, Albiges L, et al. PD-L1 expression in nonclear-cell renal cell carcinoma. Ann Oncol. 2014;25:217884.

21. Sabatier R, Finetti P, Mamessier E, Adelaide J, Chaffanet M, Ali HR, et al. Prognostic and predictive value of PDL1 expression in breast cancer. Oncotarget. 2015;6:5449-64.

22. Qing Y, Li Q, Ren T, Xia W, Peng Y, Liu GL, et al. Upregulation of PD-L1 and APE1 is associated with tumorigenesis and poor prognosis of gastric cancer. Drug Des Devel Ther. 2015;9:901-9.

23. Wang A, Wang HY, Liu Y, Zhao MC, Zhang HJ, Lu ZY, et al. The prognostic value of PD-L1 expression for non-small cell lung cancer patients: a metaanalysis. Eur J Surg Oncol. 2015;41:450-6.

\section{Submit your next manuscript to BioMed Central and take full advantage of:}

- Convenient online submission

- Thorough peer review

- No space constraints or color figure charges

- Immediate publication on acceptance

- Inclusion in PubMed, CAS, Scopus and Google Scholar

- Research which is freely available for redistribution 